\title{
Practitioner experiences from the structured implementation of evidence-based practice in primary care physiotherapy: A qualitative study
}

Siw Carlfjord, Emma Nilsing-Strid, Kajsa Johansson, Theresa Holmgren and Birgitta Öberg

The self-archived postprint version of this journal article is available at Linköping University Institutional Repository (DiVA):

http://urn.kb.se/resolve?urn=urn:nbn:se:liu:diva-15.5031

N.B.: When citing this work, cite the original publication.

This is a copy of the published version of the following article:

Carlfjord, S., Nilsing-Strid, E., Johansson, K., Holmgren, T., Öberg, B., (2018), Practitioner experiences from the structured implementation of evidence-based practice in primary care physiotherapy: A qualitative study, Journal of Evaluation In Clinical Practice.

https://doi.org/10.1111/jep.13034

Original publication available at:

https://doi.org/10.1111/jep.13034

Copyright: Wiley-Blackwell Publishing Inc.

http://wiley.com/ 


\section{Practitioner Experiences from the Structured Implementation of Evidence Based Practice in Primary Care Physiotherapy: A}

\section{Qualitative Study}

Siw Carlfjord, PT, $\mathrm{PhD}^{1}$, Emma Nilsing-Strid, PT, $\mathrm{PhD}^{2}$, Kajsa Johansson, PT, $\mathrm{PhD}^{1}$, Theresa Holmgren, PT, $\mathrm{PhD}^{1,3}$, Birgitta Öberg, $\mathrm{PT}, \mathrm{PhD}^{4}$

${ }^{1}$ Department of Medical and Health Sciences, Community Medicine, Linköping University, SE-58183 Linköping, Sweden

${ }^{2}$ University Health Care Research Centre, Faculty of Medicine and Health, Örebro University, Örebro, Sweden

${ }^{3}$ Department of Orthopaedics, Region Östergötland, Linköping, Sweden

${ }^{4}$ Professor, Department of Medical and Health Sciences, Linköping University, Linköping, Sweden

Correspondence: Siw Carlfjord, Department of Medical and Health Sciences, Division of Community Medicine, Linköping University, SE-581 83 Linköping, Sweden.

E-mail: siw.carlfjord@liu.se

Tel.: +4613282748

Running head: Implementation of evidence based practice in PHC

Keywords: Exercise; Implementation; Physiotherapy; Primary health care; Qualitative study; Shoulder pain; 


\begin{abstract}
Rationale, aims and objectives. To provide best available care the practitioners in primary health care (PHC) must have adequate knowledge about effective interventions. The implementation of such interventions is challenging. A structured implementation strategy developed by researchers at Linköping University, Sweden, was used for the implementation of an evidence based assessment and treatment programme for patients with subacromial pain among physiotherapists in PHC. To further develop strategies for implementation of evidence-based practices, it was deemed important to study the implementation from the practitioners' perspective. The aim of this study was to explore the practitioners' experiences from the implementation.
\end{abstract}

Methods. A qualitative design with focus group discussions was applied. The implementation in terms of perceptions of process and outcome was evaluated by focus group discussions with, in total, sixteen physiotherapists in the target group. Data were analysed using the method qualitative content analysis.

Results. The components of the strategy were viewed positively, the applicability and evidence base behind the programme were appreciated. The programme was perceived to be adopted, and the practitioners described a changed behaviour and increased confidence in handling patients with subacromial pain. Both patient- and provider related challenges to the implementation were mentioned.

Conclusions. The practitioners' experiences from the implementation were mainly positive. A strategy with collaboration between academy and practice, and with education and implementation teams as facilitators, resulted in changes in practice. Critical voices concerned interprofessional collaboration and that the programme was focused explicitly on the shoulder, not including other components of physical function. 


\section{Introduction}

In order to provide optimal care for patients presenting in primary health care (PHC), the practitioners must have adequate knowledge about effective interventions. It is essential that treatment methods used by physiotherapists and other health care professionals are effective and based on research evidence. In physiotherapy the evidence base increases rapidly as a result of extensive research, but there is a substantial research-practice gap and the implementation of evidence based interventions is often challenging [1,2]. One example is the recommendation to choose active treatment for patients on sick leave because of musculoskeletal disorders [3,4]. According to recent studies, however, this happens in no more than one third of cases $[5,6]$. It has also been reported that a number of methods, not proven effective, are still considered to be relevant among physiotherapists [2]. Care processes for musculoskeletal disorders, which are increasing conditions in the western world, are often complex and typically involve numerous actors, which makes implementation of new methods even more challenging $[7,8]$.

It is known from implementation studies that the translation of new findings into routine practice requires a structured implementation strategy [9-11]. Researchers at Linköping University in collaboration with Region Östergötland, Sweden have developed an implementation strategy based on research on implementation, in particular the three factors collaboration between researchers and practitioners, education with interactive components, and the role of facilitators [12]. Collaboration between researchers and practitioners is operationalized in an implementation forum (researchers and delegates from the health care provider), and is considered a core component of the strategy. In 2015 the strategy was used to implement an intervention for patients with subacromial pain among physiotherapists in PHC. 
Regarding subacromial pain there is consensus that specific exercise should be firstline treatment, and thus be offered before considering surgical interventions[13-15]. Despite this, a high proportion of patients are referred to surgery without previous conservative treatment. Ylinen et al. found that $49 \%$ of patients who had undergone surgery because of subacromial pain syndrome had not been offered a muscle training programme before surgery [16]. In a recent study, $91 \%$ of patients with subacromial pain had seen a physiotherapist preoperatively, but less than half of these patients underwent evidence-based treatment [17]. Among patients with subacromial pain on the waiting list for surgical intervention, the number who actually needed surgery decreased substantially after a 3-month period with specific exercises supervised by a physiotherapist [15]. The intervention was developed bearing in mind the importance of clinical reasoning when assessing and treating patients in the clinic, it has been scientifically evaluated and is now available as an evidence-based assessment and treatment programme $[15,18]$. The present study is part of an extensive research project aiming at evaluating different aspects of the implementation of the intervention, including the implementation strategy and the intervention itself.

The aim of the present study was to explore the practitioners' experiences from a structured implementation of an evidence based assessment and treatment programme for patients with subacromial pain, focusing on the implementation process and outcome at practitioner and patient levels.

\section{Method}

\subsection{Study design and setting}

The study was performed using a qualitative design, and is part of a larger project as described above, with physiotherapeutic treatment of subacromial pain as a pilot case. The setting was physiotherapy departments in PHC in Östergötland County, Sweden, an area with 
about 450,000 inhabitants, found to be representative for the whole country in terms of economic status, employment rates and gender distribution, and in how health care is organised [19]. To perform a qualitative evaluation of the implementation, focus group discussions were held with PHC physiotherapists recruited from the target group.

\subsection{Implementation}

The implementation forum initiated the process and physiotherapists representing the different organisations in the setting were recruited to form an implementation team. To be qualified for the implementation team, the physiotherapist had to have shoulder-specific professional skills and be trusted and respected by colleagues. The team participated in the development and local adaptation of the intervention and the educational session. The team members' role was also to facilitate the implementation by continuously answering questions about the intervention from the practitioners.

The educational intervention included an 8-hour session with both theoretical and practical components. The intervention was introduced as an "assessment and treatment programme", but in addition to the core components, it was also stressed that adaptation to meet the needs of an individual patient was allowed. The information was consolidated through an experiential learning process with problem based case studies. The case studies present patient subjective and objective assessment findings, to be reflected on in the light of the recommendations and clinical reasoning tools.

All the practicing physiotherapists in the county were invited to participate in the education, and three local sessions were held in October 2015. Participation was supported by the managers and all 140 eligible physiotherapists did take part in the educational session. 
In parallel with the implementation, a study with the aim to evaluate the programme effectiveness on patient level was launched. All practitioners who participated in the education, also received information about the effectiveness study and were encouraged to contribute to patient inclusion. The members of the implementation team had an additional task to support and coach the practitioners in the inclusion of patients for the effectiveness study.

\subsection{Data Collection}

A purposeful sampling procedure was conducted for the focus group discussions. Twelve months after initiating the implementation, four public physiotherapy practices and one private practice were contacted with an invitation to take part in a focus group, to discuss the handling of patients with subacromial pain, and their experiences of the implementation process. To facilitate the discussions, physiotherapists at the same practice but with heterogeneous backgrounds (eg, age, sex, and years as a physiotherapist) were included [20].

A semi-structured interview guide based on previous research and discussed among all the authors, was prepared in advance. Patient cases, prepared by the informants in advance, were used as a starting point for the discussion about how patients with subacromial pain are handled. This approach was chosen to encourage a discussion that included clinical reasoning decisions such as diagnosis, assessment/evaluation, treatment, and patient participation. Perceptions of the implementation of the assessment and treatment programme were also discussed.

Sixteen practitioners at the five practices participated, and five focus groups with 3-4 participants in each group took place. Most of the informants were women $(n=12$; mean age, 40 years; range, 22-58 years), and their experience as a practicing physiotherapist ranged 
from 1.5 to 28 years (mean, 14 years). The focus group discussions lasted between 1.38 and 1.46 hours.

The focus groups were carried out in October and November 2015 at the participants' workplace during working hours and were moderated by the author E.N.S. who was not part of the implementation forum or the team and had no previous relationship with any of the participants. In order to gain deeper knowledge, questions were complemented with probes, loops, and transitions. The participants were encouraged to speak freely and from their experience. The discussions were free-flowing in a friendly atmosphere. The interviews were audio recorded and transcribed verbatim.

\subsection{Data Analysis}

Data were analyzed using qualitative content analysis with an approach that is partly deductive (directed) and partly inductive as described in the literature $[21,22]$. B.Ö., E.N.S., and S.C. took part in the analysis. The transcripts were read several times to provide a comprehensive picture. The first transcript was analysed and coded independently by two researchers (E.N.S. and S.C.), and discussed until agreement on a coding strategy was established. In accordance with the aim, statements were divided into two themes, to distinguish between perceptions of the implementation process, and perceptions of outcome from the implementation. Codes based on statements that concerned the implementation process were deductively sorted into three categories, using a directed analysis [21,22]. The categories chosen; adopter characteristics, implementation object and the implementation strategy, are often used in implementation research as determinants for success [22]. Subcategories within each category emerged from the data. Codes based on statements concerning implementation outcome were analysed using an inductive method. Codes were combined into sub-categories emerging from the data, and subcategories with similar meaning 
were combined into main categories, striving to be internally homogeneous and externally heterogeneous. Consensus discussions were held continuously during the analysis, and the final version was discussed among the authors until consensus was reached. Quotes capturing the essence of the focus group discussions were selected to illustrate the different subcategories [20]. The selected quotes from the transcripts were translated into English, then retranslated into Swedish, to ensure that their meaning was retained.

\subsection{Ethical Considerations}

The study was approved by the Research Ethics Committee of the Faculty of Health Sciences of Linköping University, Sweden (Dnr 2014/343-31). The participants provided informed consent after receiving both written and oral information about the study, including the aspects of voluntary participation, the possibility of withdrawing at any time without explaining why, and that the responses to questions would be handled confidentially and presented in a way that does not allow the identification of individuals.

\section{Results}

The results are presented according to the two areas of interest already defined in the aim, the implementation process and implementation outcome. Categories and sub-categories pertaining to each area are illustrated in Table 1. The categories are summarized in text and are followed by descriptions of the sub-categories which are supported by quotes from the informants. Words in brackets within the quotes are explanations made by the authors, and (...) means that some words have been left out. The focus group participants are presented by group and number. 
Table 1. Overview of the categories and subcategories presented in the Results section, according to the two areas under study

\begin{tabular}{|c|c|c|c|c|c|c|c|}
\hline Area & \multicolumn{3}{|c|}{ Implementation process } & \multicolumn{4}{|c|}{ Implementation outcome } \\
\hline Categories & $\begin{array}{l}\text { Implementation } \\
\text { strategy }\end{array}$ & $\begin{array}{l}\text { Implementation } \\
\text { object }\end{array}$ & $\begin{array}{l}\text { Adopter } \\
\text { characteristics }\end{array}$ & Adoption & Challenges & $\begin{array}{l}\text { Fidelity vs } \\
\text { adaptation }\end{array}$ & $\begin{array}{l}\text { Programme } \\
\text { effects }\end{array}$ \\
\hline $\begin{array}{l}\text { Sub- } \\
\text { categories }\end{array}$ & $\begin{array}{l}\text { - Collaboration } \\
\text { academy - } \\
\text { clinic } \\
\text { - Team } \\
\text { - Education }\end{array}$ & $\begin{array}{l}\text { - Reliability } \\
\text { - Applicability } \\
\text { - Criticism }\end{array}$ & $\begin{array}{l}\text { - Competence } \\
\text { - Ambiguity }\end{array}$ & $\begin{array}{l}\text { - Programme } \\
\text { adoption } \\
\text { - Experienced } \\
\text { changes }\end{array}$ & $\begin{array}{l}\text { - Patient- } \\
\text { related } \\
\text { - Provider- } \\
\text { related }\end{array}$ & $\begin{array}{l}\text { - Modification } \\
\text { - Complementary } \\
\text { treatment }\end{array}$ & $\begin{array}{l}\text { - Patient } \\
\text { recovery } \\
\text { - Lack of } \\
\text { observed } \\
\text { effect }\end{array}$ \\
\hline
\end{tabular}

\subsection{Perceptions of the implementation process}

The statements regarding the implementation process were deductively divided into the three categories: Implementation strategy, Implementation object and Adopter characteristics.

\subsubsection{The implementation strategy}

The strategy used for the implementation consisted of three components, collaboration between academy and clinic, an implementation team and an educational session, and the perceptions reported by the informants are described accordingly.

The informants appreciated the collaboration between clinic and academy, interpreted as leader support and a determined intention that the programme was to be implemented in practice. They also appreciated the fact that all units were involved. The members of the implementation team were perceived as reliable and competent and their services were appreciated. Regarding the educational session, the informants appreciated the combination of theory and practical training, perceived that the knowledge provided was new and based on evidence, and described the teachers, also including researchers who had taken part in generating the evidence, as competent. 
It is new of its kind, a very nice collaboration between university and clinic, and you can see... I think it is great (1:4)

We are all allowed to participate on paid working hours, because it is like a sanction from the county council, it is not about money, but something that is to be implemented $(5: 2)$

She is really skilled when it comes to shoulder treatment, so if she can spend some time we are really grateful to have someone who sees with new eyes, put other questions, makes you see clearer, from outside (4:2)

And also to be shown how to perform the exercises, and how to test this and not only that, I mean, you can always read a study about shoulder exercise and treatment, but then to apply it in practice... (2:3)

\subsubsection{The implementation object}

The implementation object in the present study is the programme for diagnosis and treatment of subacromial pain. As described in the methods section a study was launched in parallel with the implementation of the programme and part of the discussions in the focus groups concerned the study. Only statements concerning the programme are included in this category, comprising reliability, applicability and criticism.

The informants appreciated the programme being evidence based, and found it highly reliable. Tests for assessment, exercises for treatment and evaluation instruments were found applicable. There was however, also criticism, in terms of the programme being too narrow, lacking factors important for the patients it is intended for, and not applying a holistic view on physical function. 
There seems to be a solid work behind it [the programme] it seems thoroughly elaborated (2:3)

When we treat a shoulder we should also consider core stability, but I can't see that we do that here, we do not consider the whole body, only focus on the shoulder (1:4)

\subsubsection{Adopter characteristics}

This category is based on statements made by the informants, mostly concerning assessment and treatment of patients, where their own competence is reflected. Two subcategories could be identified; competence and ambiguity. Regarding competence the informants expressed a high level of competence in the area of treating patients with subacromial pain, they had confidence and experience and showed a high level of clinical reasoning. However, they also stated that diagnosing the condition is often difficult and challenging.

Often you get a clear picture about what it is, and you think this must be subacromial pain, it is there, in your mind before starting the examination, and then those tests, (...) I was familiar with them before (1:1)

And there is often a lot of other things too, not only subacromial pain, so even if those tests are positive there may be so much more (2:2)

The informants also judged their own performance, labelled here as ambiguity, and stated that sometimes they do not act according to their own best knowledge. They also expressed a need for continuing education and opportunities for reflection.

After some years at work you get your routines, you choose the tests that you are comfortable with (1:4) 
It is good to have some repetition, to see how others do and listen to them (...) when it comes to techniques and skills and so on, talk about it, see how to do it, that goes for everything in physical therapy (3:2)

\subsection{Perceived outcome from the implementation}

The area implementation outcome resulted in four categories inductively emerging from the data, the categories Adoption, Implementation challenges, Fidelity/Adaptation, and Programme effects.

\subsubsection{Adoption}

According to the informants, the programme was perceived to be adopted by the practitioners. They described how they used the assessment methods, the recommended exercises for treatment and to some extent the follow-up instruments, and they did it with higher precision than they used to. For some of the practitioners this represented a change, while others claimed that they already did handle their patients according to the programme. They also described changes due to the implementation, in terms of increased confidence and competence in handling the patients, but also in increased collaboration and shared views among professionals (general practitioners (GPs), surgeons, physiotherapists). An increase in expecting the patients to take responsibility for their recovery was mentioned as well.

You try to see them again a bit sooner (...) and check their [exercise] performance more thoroughly than you used to do (3:2)

You may have been too cautious, recommended easy exercises like retraction or circulation (...) and when you started to add more of strengthening exercise they discover 
how to stabilize, and they see results, so, yes I introduce strengthening exercise earlier now $(4: 3)$

But I have more confidence in these tests, they are the right ones to do, since they are based on research and they are recommended in this way (2:2)

They [the patients] were recommended these exercises in PHC but they did not recover completely, then they see an orthopaedic surgeon who recommends the same exercises, the ones they already did (...) then I think it results in better adherence to the recommended exercises, I think that is part of the success too (4:1)

But you have to be clear when talking to the patient, that I am here to guide and help you, but you are the one who must do the work, because if they are not willing to do that it will be difficult $(5: 1)$

\subsubsection{Implementation challenges}

A number of challenges for the implementation of the new programme were mentioned, and could be divided into patient-related and provider-related challenges. Among patients, motivation was considered a challenge, and the practitioners have to use pedagogic skills to motivate patients. Pain or fear were other problems that the practitioners had to deal with in order to apply the programme. On provider level, professional collaboration was mentioned, as there are still GPs who do not consider the opportunity to refer the patient to a physiotherapist, or are not willing to wait for exercise treatment effects before they suggest surgery. Some practitioners had witnessed colleagues who were reluctant to adopting the program, but the informants did not know the reason for that. Organizational factors like time constraints were mentioned, as it is not always possible to allocate the time needed for each 
patient. Long term concerns were that it is important that new staff members are trained regarding the programme, or that repeated education is provided.

[If a patient says] "I'm ready to engage in this, I will do what it takes to be cured" then it's easy, but those who say 'Just give me some stretching, and I will be OK", then maybe we shouldn't even initiate the treatment (4:1)

But it must be acknowledged that this is the way we do it [handle this patient category] because we know that it works, but then everyone must stick to that, if the doctors are not "in" it is of no use, they will walk their own path anyway (1:1)

Ifind that it [the programme] has helped my patients, and me in my profession, but when I look at those [colleagues] who did not use it, is it because they are too lazy or is it that they do not like it? (1:4)

\subsubsection{Fidelity versus adaptation}

The practitioners mentioned how they modify the programme in terms of number of exercises, number of repetitions, level of resistance and so on, depending on the patient's problems. This could be considered adaptation, but is to a certain degree built in to the programme which is meant to be flexible and adaptable to suit the clinical variety present inpatients with subacromial pain. The practitioners also described that they add complementary methods such as pain treatment, taping or exercises to increase range of motion in order to create a condition where the programme can be fully applied.

Based on what I know from my patients, if you do too much you have a bad result, so why not start with just doing one thing (3:2) 
Just to obtain pain relief, nothing else, in order to be able to do the exercises, since that is the treatment I aim for $(1: 1)$

In particular with older patients. I had one old lady where you couldn't even start [with the programme], you had to begin with just movement exercise, and then add some static strength exercise (2:2)

\subsubsection{Programme effects}

The practitioners gave a number of examples of patients who had recovered, completely or partly, from their condition after completing the programme. Some had the experience that those with a typical subacromial pain with an impingement phenomenon were the ones who recovered, while others had tried the programme also for other shoulder conditions, and found it effective. There were also statements that there are other programmes with similar effectiveness, and experiences of patients who did not benefit from application of the programme.

It took like, three to four weeks before she felt better, noticeably better, with less pain in extreme positions, she could sleep on her left side, felt a bit stronger (3:2)

Since she had no pain, I mean, no painful arc, it was hard to differentiate [from other diagnosis], but she did recover, and that is what's important (3:3)

I used to work according to another programme, and that was effective too, I don't think they recover faster with this programme, so, it's about the same (4:1)

Gave her instructions to continue with the exercises, but less intensive, depending on her pain... and she came back after two weeks, no improvement, rather worse, with severe pain in some movements $(2: 2)$ 


\section{Discussion}

The main findings from this study were that, regarding the implementation process, the practitioners had positive experiences from the different components of the strategy, and they appreciated the applicability and the evidence base behind the programme. Regarding implementation outcome, the programme was adopted, and the practitioners described a change in their behaviour and increased confidence. The programme seems to be applied according to the protocol, but complementary treatment is common, and challenges are both patient- and provider related. In general the practitioners found the programme effective on a patient level.

While adopting the programme, the practitioners described how they adapted it based on their clinical reasoning, according to the perceived needs of each patient, but not always evidence-based. It could be discussed whether or not this is a threat against fidelity, as the programme does allow for adaptation, and clinical reasoning is encouraged. Adapting an evidence-based method may be necessary, but it must be considered that there is a limit when it is no longer based on evidence. Chambers and colleagues argue that sustainability is dynamic, and that a certain degree of adaptation is inevitable [23]. Our informants also used the programme for patients that were not diagnosed with subacromial pain, but had other shoulder pain conditions. This is also to a certain degree an adaptation, and is hard to impede. It is, however, also an indication of confidence in the programme to be effective in other circumstances.

When guidelines or new programmes for treatment are introduced in different areas of health care, there is sometimes a reluctance among the practitioners, who may experience a threat to their current performance $[24,25]$. Among our informants there were very few statements in that direction, which might be caused by a selection bias - only those who are 
positive to guidelines and evidence-based programmes chose to participate in the interviews. There were, however, statements about colleagues being reluctant, but without further elaboration regarding this opinion.

The fact that the programme applied a mainly biomedical approach, not including psychological or social aspects may have been positive for the implementation outcome, as it is known that physiotherapists are best prepared to handle biomedical problems [26,27]. Criticism against the programme concerned that it was not perceived to be holistic in a biomedical perspective, as it targets only shoulder function. This should be considered in future development of treatment guidelines. The general view was that the informants had found the programme to have positive effect on patients, which strengthened their confidence in the programme. In terms of innovation characteristics according to Rogers this could be referred to as observability - observed effects increase implementation outcome [28]. The programme was also found to encourage patient responsibility, as the practitioners seem to have been strengthened in their efforts to encourage self-care in that sense. An evaluation of the programme on patient level also indicates increased patient responsibility for their own treatment [29].

Challenges for the implementation mentioned by the practitioners concerned both patients and professionals. The collaboration between GPs, orthopaedic surgeons and physiotherapists was very much appreciated, but when the collaboration did not work this caused a high level of frustration. An example of this could be if a patient is referred to surgery without completing the recommended programme, as it gives conflicting messages to the patients. The present study did not include a team approach except for the mentioned collaboration when referring patients. A more comprehensive approach with a broader strategy including all organizational levels and professional groups has been suggested as a new model of care to support the implementation of new practices in health care [30]. At 
patient level a challenge is a lack of motivation, sometimes because the patients believe that surgery is an easier way out. Engaging the patient in terms of shared decision making could be a way to overcome this [31].

The opportunity in this study to build on researcher/provider collaboration is considered a success factor. The practitioners mentioned a sensation of support from top level management. An implication from this is that the concept of an implementation forum needs to be further developed and evaluated, also in other settings.

The allocation of an implementation team seems to have been successful, and is a strategy that has been advocated in implementation research [9]. The team members were handpicked for having specific skills but also to be trusted by their colleagues drawing on the theory of social influence [32]. Confidence in the team members was illustrated by the practitioners who described how they could ask a team member for a second opinion when they had doubts about the diagnosis. The recruitment of these individuals, sometimes called opinion leaders or champions, has been shown to be crucial in an implementation process [33].

The educational session, although not innovative as a concept, also proved effective and was appreciated by the practitioners. A very important factor regarding the educational sessions was that researchers who had contributed to current evidence in the area, and who had developed the intervention, also took part in the educational sessions. The pedagogic approach with case based studies and the explicit focus on clinical reasoning might have contributed to the positive evaluation. $[1,34,35]$.

In a recent review, Dziedzic et al. state that there is a paucity of evidence on which approaches work to increase the uptake of best practice in health care, also suggesting that implementation and its impact should be evaluated in real-world applications [36]. To a 
certain degree, the present study contributes to the expansion of knowledge in this area, because it was performed in a real-world clinical setting. To our knowledge the strategy of combining an implementation forum (or similar) and implementation team with selected individuals and an education with a case based approach has not been described in the literature. It may not always be possible to have a local forum for collaboration between academy and health care practice, but where it is feasible opportunities for collaboration can be developed.

Further studies are needed to evaluate the implementation strategy used in this study in other settings, with both qualitative and quantitative designs and also considering cost effectiveness. Patient reported outcomes may also be of interest.

There are limitations that should be kept in mind when interpreting the results from this study because of the study design and the nature of the research. All the authors are physiotherapists, which could be considered a strength, or a limitation, because the perspective of another profession could have enabled a different interpretation. Consensus discussions between the authors were held throughout the analysis process to enhance credibility, and representative quotations capturing the essence of what was said were selected to illustrate the different categories. The focus group discussions were performed by one researcher (E.N.S.), who had no previous relationship with any of the participants or had not been previously involved in the research project.

Qualitative designs produce context-specific results ${ }^{37}$ and, considering that the study was conducted in PHC in one county council in Sweden, although highly representative for the country, the transferability of the findings might be limited [37]. However, the exhaustive descriptions of the context, informants, and process of analysis help the reader to decide whether the results are applicable in another context. Credibility is strengthened by the 
purposeful sampling of physiotherapists who had participated in the educational session. These physiotherapists differed in gender, age, and experience, which contributed to a rich description of the phenomena under study, i.e. the implementation of evidence-based physiotherapy practice for patients with subacromial pain.

We conclude that the practitioners' experiences from the implementation were mainly positive. A strategy with collaboration between academy and practice, and with education and implementation teams as facilitators, resulted in changed behaviour and improved confidence in handling subacromial pain in primary care. The critical voices that appeared concerned interprofessional collaboration and the programme being too much focused on the shoulder, not including other components of physical function.

\section{Acknowledgment}

The authors are grateful to the primary care physiotherapists who gave their time and shared their experiences in the focus group discussions. 


\section{References}

1. Maher CG, Moseley AM, Sherrington C, et al. A description of the trials, reviews and practice guidelines indexed in the PEDro database. Phys Ther. 2008;88:1068-1077.

2. Bernhardsson S, Öberg B, Johansson K, et al. Clinical practice in line with evidence? A survey among primary care physiotherapists in western Sweden. J Eval Clin Pract. 2015;21:1169-1177.

3. Schaafsma FG, Whelan K, van der Beek AJ, et al. Physical conditioning as part of a return to work strategy to reduce sickness absence for workers with back pain. Cochrane Database Syst Rev. 2013;30:CD001822.

4. van Vilsteren M, van Oostrom SH, de Vet $\mathrm{HCW}$, et al. Workplace interventions to prevent work disability in workers on sick leave. Cochrane Database Syst Rev. 2015;10:CD006955.

5. Wahlin C, Ekberg K, Persson J, et al. Association between clinical and work-related interventions and return-to-work for patients with musculoskeletal or mental disorders. J Rehabil Med. 2012;44:355-362.

6. Nilsing E, Soderberg E, Oberg B. Sickness certificates in Sweden: did the new guidelines improve their quality? BMC Public Health. 2012;12:907.

7. March L, Smith E, Hoy D, et al. Burden of disability due to musculoskeletal (MSK) disorders. Best Pract Res Clin Rheumatol. 2014;28:353-366.

8. Hoy DG, Smith E, Cross M, et al. Reflecting on the global burden of musculoskeletal conditions: lessons learnt from the global burden of disease 2010 study and the next steps forward. Ann Rheum Dis. 2015;74:4-7. 
9. Fixsen DL, Naoom SF, Blase KA, et al. Implementation Research: A Synthesis of the Literature. Tampa, FL: University of South Florida, Lou-is de la Parte Florida Mental Health Institute; 2005.

10. Graham ID, Logan J, Harrison MB, et al. Lost in knowledge translation: Time for a map? J Contin Educ Health Prof. 2006;26:13-24.

11. Grol R, Wensing M, Eccles M, et al. Improving Patient Care: The Implementation of Change in Health Care. 2nd ed. Chichester: Wiley Blackwell; 2013.

12. Nutley S M, Walter I, Davies H T O. Using evidence : how research can inform public services. Bristol: Policy Press; 2007.

13. Björnsson Hallgren HC, Holmgren T, Oberg B, et al. A specific exercise strategy reduced the need for surgery in subacromial pain patients. Br J Sports Med. 2014;48:14311436.

14. Hanratty CE, McVeigh JG, Kerr DP, et al. The effectiveness of physiotherapy exercises in subacromial impingement syndrome: a systematic review and meta-analysis. Semin Arthritis Rheum.2012;42:297-316.

15. Holmgren T, Björnsson Hallgren H, Öberg B, et al. Effect of specific exercise strategy on need for surgery in patients with subacromial impingement syndrome: randomised controlled study. BMJ. 2012;344:e787.

16. Ylinen J, Vuorenmaa M, Paloneva J, et al. Exercise therapy is evidence-based treatment of shoulder impingement syndrome. Current practice or recommendation only. Eur J Phys Rehabil Med. 2013;49:499-505.

17. Husdal Dørum, I, Heir S, Solheim E, et al. Implementation of conservative treatment prior to arthroscopic subacromial decompression of the shoulder. Knee Surg Sports Traumatol Arthrosc. 2016; doi:10.1007/s00167-016-4091-4. 
18. Cruz E, Moore A, Cross V. A qualitative study of physiotherapy final year students' perceptions of clinical reasoning. Man Ther. 2012;17:549-553.

19. Statistics Sweden. Stockholm, Sweden, SCB; 2012. Available at: http://www.scb.se (accessed Feb 8 2018).

20. Krueger RA, Casey MA, editors. Focus Groups: A Practical Guide for Applied Research. Thousand Oaks, CA: Sage; 2009.

21. Hsieh H-F, Shannon S E. Three approaches to qualitative content analysis. Qualitative Health Research 2005;15:1277-1288.

22. Mayring P. Qualitative Content Analysis [28 paragraphs]. Forum Qualitative Sozialforschung / Forum: Qualitative Social Research, 2000;1(2), Art. 20.

23. Chambers DA, Glasgow RE, Stange KC. The dynamic sustainability framework: addressing the paradox of sustainment amid ongoing change. Implement Sci. $2013 ; 8: 17$.

24. Court AJ, Cooke A, Scrivener A. They're NICE and neat, but are they useful? A grounded theory of clinical psychologists' beliefs about and use of NICE guidelines. Clin Psychol Psychother. 2016; doi:10.1002/cpp.2054.

https://onlinelibrary.wiley.com/doi/abs/10.1002/cpp.2054

25. Figg-Latham J, Rajendran D. Quiet dissent: the attitudes, beliefs and behaviours of UK osteopaths who reject low back pain guidance: a qualitative study. Man Ther. 2016; doi: 10.1016/j.math.2016.10.006. https://www.sciencedirect.com/science/article/pii/S0165489616301299

26. Gardner T, Refshauge K, Smith L, McAuley J, Hubscher M, Goodall S: Physiotherapists' beliefs and attitudes influence clinical practice in chronic low back pain: a systematic review of quantitative and qualitative studies. J Physiother. 2017;63(3):132-143. 
27. Synnott A, O’Keeffe M, Bunzli S, Dankaerts W, O'Sullivan P, O'Sullivan K: Physiotherapists may stigmatise or feel unprepared to treat people with low back pain and psychosocial factors that influence recovery: a systematic review. J Physiother. 2015;61(2):68-76.

28. Rogers, E. M. Diffusion of Innovation. New York: Free Press; 2003.

29. Björnsson Hallgren H, Adolfsson LE, Johansson K, Öberg B, Peterson A, Holmgren T. Specific exercises for subacromial pain. Acta Orthop. 2017;88(6):600-605.

30. Briggs AM, Towler SC, Speerin R, March LM. Models of care for musculoskeletal health in Australia: now more than ever to drive evidence into health policy and practice. Aust Health Rev. 2014;38:401-405.

31. Elwyn G, Frosch D, Thomson R, et al. Shared Decision Making: A model for clinical practice. J Gen Intern Med. 2012;27(10):1361-1367.

32. Mittman B, Tonesk X, Jacobson P. Implementing clinical practice guidelines: social influence strategies and practitioner change. Qual Rev Bull. 1992;18:413-422.

33. Greenhalgh T, Donaldson L, Bate P, et al. Diffusion of Innovations in Health Service Organisations: A Systematic Literature Review. London: Blackwell Publishing; 2005.

34. Hmelo-Silver CE. Problem-Based Learning: What and How Do Students Learn? Educ Psychol Rev. 2004;3:235-266.

35. Loughlin M, Bluhm R, Buetow S, Borgerson K, Fuller J. Reasoning, evidence, and clinical decision-making: The great debate moves forward. J Evaluation Clin Pract. 2017;23(5):905-914

36. Dziedzic SK, French S, Davis AM, et al. Implementation of musculoskeletal Models of Care in primary care settings: theory, practice, evaluation and outcomes for 
musculoskeletal health in high-income economies. Best Pract Res Clin Rheumatol. 2016;30:375-397.

37. Graneheim U H, Lundman B. Qualitative content analysis in nursing research: concepts, procedures and measures to achieve trustworthiness. Nurse Educ Today. 2004;24:105112. 
